\title{
PERILAKU NON PLAYER CHARACTER (NPC) PADA GAME FPS “ZOMBIE COLONIAL WARS” MENGGUNAKAN FINITE STATE MACHINE (FSM)
}

\author{
Yulia Windi Astuti ${ }^{1)}$, Amak Yunus ${ }^{2)}$, Moh. Ahsan ${ }^{3)}$ \\ ${ }^{1,2,3)}$ Teknik Informatika Fakultas Sains Dan Teknologi Universitas Kanjuruhan Malang, Indonesia \\ email :yuliawindilo@gmail.com ${ }^{l)}$,amakyunus@unikama.ac.id ${ }^{2)}$,ahsan@unikama.ac.id ${ }^{3)}$
}

\begin{abstract}
Abstrak
Penerapan kecerdasan buatan (AI) dalam sebuah game merupakan salah satu inovasi teknologi. Variasi game salah satunya adalah First Person Shooter (FPS). Kecerdasan buatan yang dikembangkan untuk merancang perilaku Non Player Character (NPC) dimana NPC dapat berperilaku secara bertahap dan berurutan sesuai state. Oleh sebab itu dikembangkan dengan menerapkan metode Finite State Machine (FSM) pada game "Zombie Colonial Wars". Penerapan metode Finite State Machine (FSM) dalam game Zombie Colonial Wars berfungsi untuk melihat variasi respon perilaku pada NPC sesuai interaksi yang dilakukan oleh player. Hasil dari penelitian ini adalah game zombie colonial wars menghasilkan sebuah kecerdasan buatan pada perilaku NPC dengan mengimplementasikan metode finite state machine sehingga musuh dapat berperilaku berdasarkan interaksi yang telah dilakukan oleh player.
\end{abstract}

Kata Kunci :

Game, NPC, Finite State Machine, Kecerdasan Buatan.

\begin{abstract}
The application of artificial intelligence (AI) in games is one of the technological innovations. One of the game variations is First Person Shooter (FPS). Artificial intelligence was developed to design the behavior of Non Player Character (NPC) where NPC can behave in stages and sequentially according to the state. Therefore it was developed by applying the Finite State Machine (FSM) method in the game "Zombie Colonial Wars". The application of the Finite State Machine (FSM) method in the Zombie Colonial Wars game serves to see variations in behavior response on the NPC according to the interaction performed by the player. The result of this research is that the zombie colonial wars game produces an artificial intelligence on the behavior of NPCs by implementing the finite state machine method so that the enemy can behave based on the interactions that have been performed by the player.
\end{abstract}

Keywords :

Game, NPC, Finite State Machine, Artificial Intelligence

\section{PENDAHULUAN}

Kecerdasan Buatan pada game First Person Shooter biasanya terdiri atas perencanaan path, mengambil item, menggunkan item, dan berperang (Asmiatun, 2016). Game perang yang dibangun berbasis First Person Shooter (FPS) dengan mengevaluasi perilaku NPC dan menentukan teknik kecerdasan buatan yang sesuai untuk NPC, agar NPC dapat bergerak secara otomatis dan respon perilaku dapat sesuai dengan game untuk membuat perilaku taktis menyerang player. Penentuan perilaku NPC dibuat dengan metode Finite State Machine (FSM). Finite State Machine (FSM) merupakan sistem state per state yang terdapat pada sebuah game yang merupakan perancangan pada sistem kontrol dimana menggambarkan tingkah laku atau prinsip kerja sistem yang menggunakan tiga hal yaitu, state (keadaan), event (kejadian) dan action (aksi). Penelitian sebelumnya dilakukan oleh Fadel Marzian (2016), dengan judul Game RPG "The Royal Sword" Berbasis Desktop Dengan Menggunakan Metode Finite State Machine (FSM). dimana penggunaan metode Finite State Machine (FSM) pada game RPG the royal sword berfungsi untuk batas perpindahan misi atau level 
agar game menjadi lebih teratur dan tertata dengan penyelesaian secara bertahap dan berurutan. Oleh sebab itu pada penelitian ini, agar zombie dapat berperilaku secara bertahap dan berurutan sesuai state maka dikembangkan dengan menggunakan metode Finite State Machine (FSM) pada game "Zombie Colonial Wars". Penerapan metode Finite State Machine (FSM) dalam game Zombie Colonial Wars berfungsi untuk melihat variasi respon perilaku pada NPC sesuai interaksi yang dilakukan oleh player.

Berdasarkan latar belakang diatas, maka dalam penelitian ini terdapat gagasan untuk mengembangkan sebuah game dari penelitian sebelumnya untuk mengetahui variasi respon perilaku NPC dengan metode Finite State Machine (FSM) pada Non Player Character (NPC) yang berjudul "Perilaku Non Player Character (Npc) pada Game Fps "Zombie Colonial Wars" menggunakan Finite State Machine (Fsm)".

Tujuan penelitian ini adalah mengetahui variasi respon perilaku NPC dengan menggunakan metode Finite State Machine (FSM) pada Non Player Character (NPC) pada Artificial Intelegent (AI) NPC musuh dalam game "Zombie Colonial Wars". Agar penelitian ini dapat terarah dengan jelas dan permasalahan yang akan diteliti tidak meluas pada luar batas penelitian, maka batasan masalah dalam penelitian ini adalah :

1. Game yang dibangun bergenre First Person Shooter (FPS).

2. Game bersifat Single Player berbasis desktop 3 dimensi dan game menggunakan software game unity $3 \mathrm{~d}$ dengan bahasa pemograman Java Script dan C\#.

3. Game hanya ada 2 level beginner dan expert .

4. Metode yang digunakan adalah Finite State Machine (FSM).

5. Game tidak membutuhkan penggunaan data dari koneksi internet.

6. Environment dan animation pada game ini masih mengambil dari assets unity $3 \mathrm{~d}$ dan masih belum terdapat efek-efek menarik pada game.

7. Game terlihat masih kaku dan item-item di sekitar terlihat kosong pada latar game.

\section{METODE / ALGORITMA}

Pendekatan yang dilakukan dalam penelitian ini adalah metode penelitian pengembangan (Research \& Development). Menurut Sugiyono (2010:407), metode penelitian pengembangan merupakan metode penelitian yang digunakan untuk menghasilkan produk tertentu.

\subsection{Penentuan Konsep}

Tahap penentuan konsep merupakan tahap dimana akan ditentukan konsep game yang nantinya akan dikembangakan. Game ini bernama "Zombie Colonial Wars", yaitu game First Person Shooter yang terdiri satu player dan musuh berupa zombie serta asset lain yang berhubungan dengan environment game. Game yang dibangun merupakan Shooting Game yang merupakan jenis game First Person Shooter (FPS) dimana pada game ini akan dirancang sebuah perilaku Non Player Character (NPC) dengan kecerdasan buatan menggunakan Finite State Machine (FSM). Fokus dari penelitian ini adalah menerapkan kecerdasan buatan/artificial intelegent (AI) NPC musuh yang efektif dalam game "Zombie Colonial Wars" dengan menggunakan finite state machine berdasarkan interaksi yang dilakukan oleh player.

Berikut ini adalah konsep yang ada pada game ini :

1. Sistem Single Player

2. Merancang perilaku NPC

3. Grafik game 3D

4. Interaksi game menggunakan Mouse dan Keyboard sebagai kontrol play 
URL : https://jurnal.machung.ac.id/index.php/kurawal

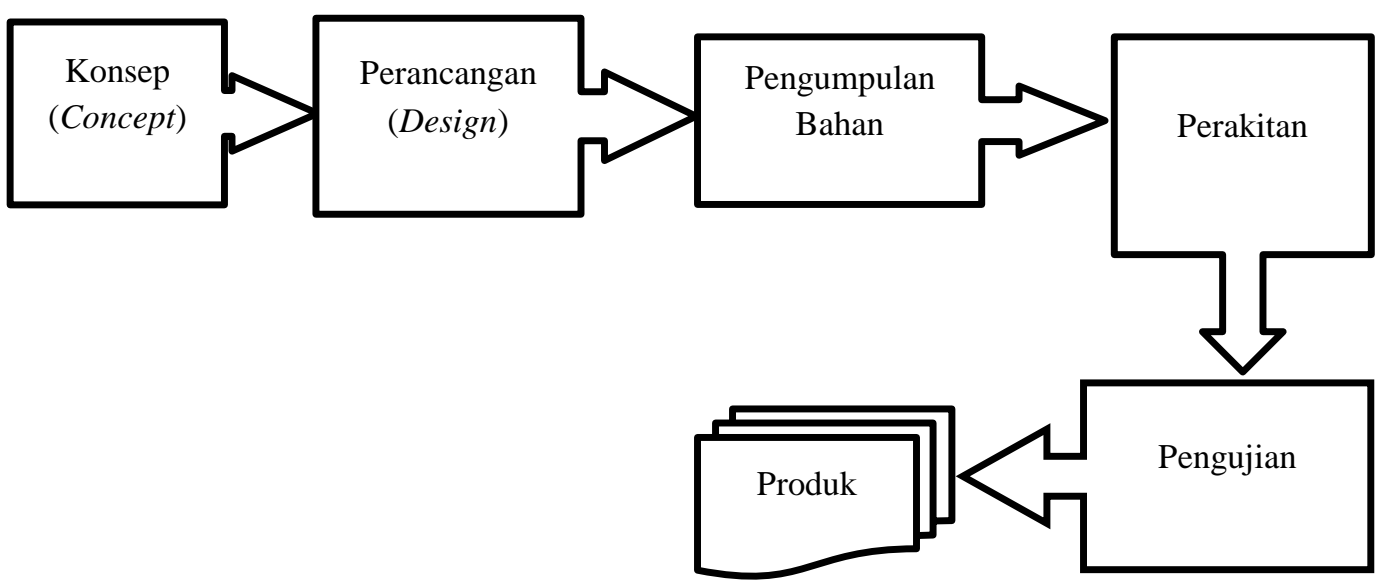

Gambar 1 Tahap-Tahap Penelitian Metode Research and Development



Gambar 2 Rancangan FSM NPC musuh

\subsection{Perancangan}

Tahap perancangan merupakan tahap selanjutnya yang dilakukan setelah menentukan konsep game, dimana pada tahap perancangan akan dilakukan rancangan / design terhadap pengembangan game yang dibuat sebagai berikut :

A. Perancangan Gameplay

Gameplay adalah pola yang ditetapkan melalui aturan permainan, hubungan antara pemain dengan game, tantangan, dan cara untuk mengatasi tantangan tersebut. Game dirancang menjadi dua level yaitu Beginner dan Expert tiap level memiliki tingkat kesulitan yang berbeda antara lain:

a. Beginner

1.) Senjata yang disediakan di level ini adalah senjata mesin yang mempunyai damage serang besar dan jumlah peluru banyak.

2.) Pergerakan NPC (zombie) lambat.

3.) Damage serangan NPC (zombie) terhadap player sedikit.

b. Expert

1) Senjata yang disediakan di level ini adalah handgun yang mempunyai damage serang lebih kecil dari senjata mesin dan jumlah peluru yang lebih sedikit.

2) Pergerakan NPC (zombie) cepat. 
URL : https://jurnal.machung.ac.id/index.php/kurawal

3) Damage serangan zombie terhadap player lebih besar dari level beginner.

\section{B. Perancangan FSM NPC Musuh}

Penjelasan Rancangan FSM NPC musuh di atas :

1. Idle : Game dimulai dan NPC berada pada state idle saat jauh dari jangkauan player.

2. Mengejar : Saat player terlihat dan dekat dengan radius serang NPC maka NPC akan mengejar player dan jika player berlari menjauhi NPC dan tidak berada pada radius serang NPC maka NPC akan kehilangan player dan kembali pada state idle.

3. Menyerang : Saat player terjangkau oleh NPC maka NPC akan menyerang player. Saat player lari NPC berpindah ke state mengejar dan saat player semakin menjauh dari radius serang NPC maka NPC akan pindah ke state idle.

4. Mati : Player akan mati jika kesehatan player tidak ada.

\section{Deskripsi NPC Musuh}

Karakter Npc musuh yang dibuat pada game ini adalah zombie. NPC musuh ini dalam keadaan posisi idle saat game dimulai dan jika player berada dekat dengan zombie, maka perilaku gerak zombie menjadi mengejar player. NPC musuh juga dapat menyerang player jika berada dekat pada radius serang zombie dan akan menyerang secara terus menerus jika player masuk ke dalam radius serang zombie. NPC musuh pada game zombie colonial wars memiliki 3 keadaan yaitu pada saat idle, mengejar dan menyerang.

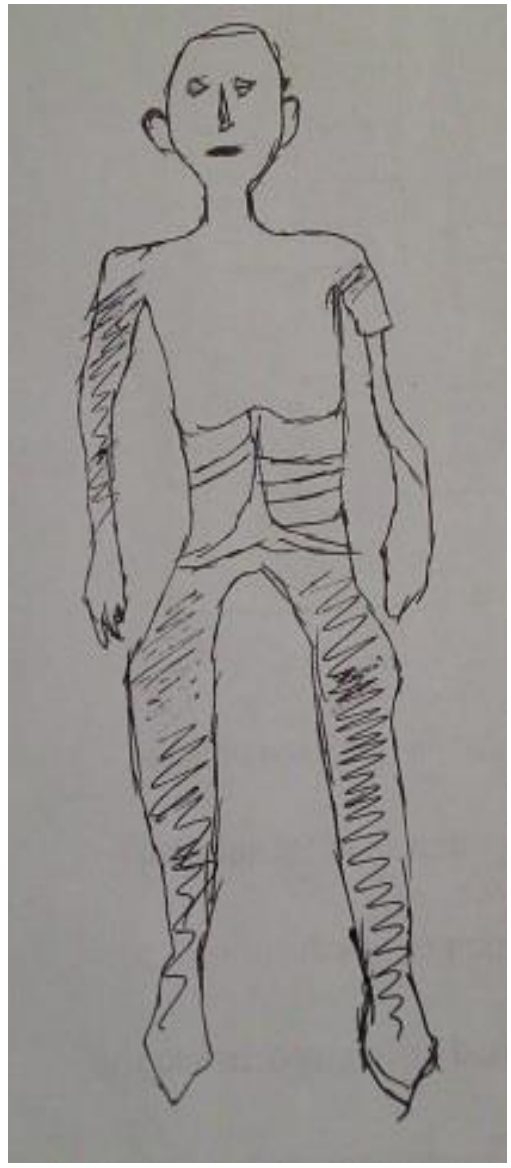

Gambar 3 Zombie idle



Gambar 4 Zombie Mengejar 




Gambar 5 Zombie Menyerang

Keterangan :

\section{Gambar 1}

NPC musuh yang memiliki pergerakan idle dimodelkan seperti orang yang sedang dalam keadaan diam dan sesekali menggerakkan tangan.

\section{Gambar 2}

NPC musuh yang sedang mengejar player dimodelkan sebagai zombie yang berlari menuju kearah player.

\section{Gambar 3}

NPC musuh yang sedang menyerang player adalah zombie yang berlari menuju ke arah player. Segi animasi sama dengan musuh yang sedang mengejar, tetapi pada saat menyerang NPC musuh memiliki kecepatan yang lebih tinggi dan mendekati player sampai menyentuhnya sehingga berubah pada keadaan menyerang.

\section{Skenario Perubahan Perilaku Pada NPC Musuh}

Skenario dalam perubahan perilaku NPC musuh dibuat skenario untuk game yang dijadikan simulasi atau uji coba. Karakter dibagi menjadi dua bagian, yaitu pemain (player) dan NPC musuh yang menjadi obyek penelitian ini. NPC musuh mempunyai perilaku menyerang sekaligus variable yang mempengaruhi peubahan pada perilaku seperti pada tabel dibawah. Skenario respon NPC musuh idle, mengejar dan menyerang.

Tabel 1 Skenario Perubahan Perilaku Pada NPC Musuh

\begin{tabular}{c|l|l}
\hline NPC & Variabel Input Perilaku & Variabel Output Perilaku \\
\hline $\begin{array}{c}\text { NPC } \\
\text { Musuh }\end{array}$ & Jarak terhadap player & $\begin{array}{l}\text { Idle, mengejar } \text { player } \\
\text { Menyerang } \text { player }\end{array}$ \\
\hline
\end{tabular}




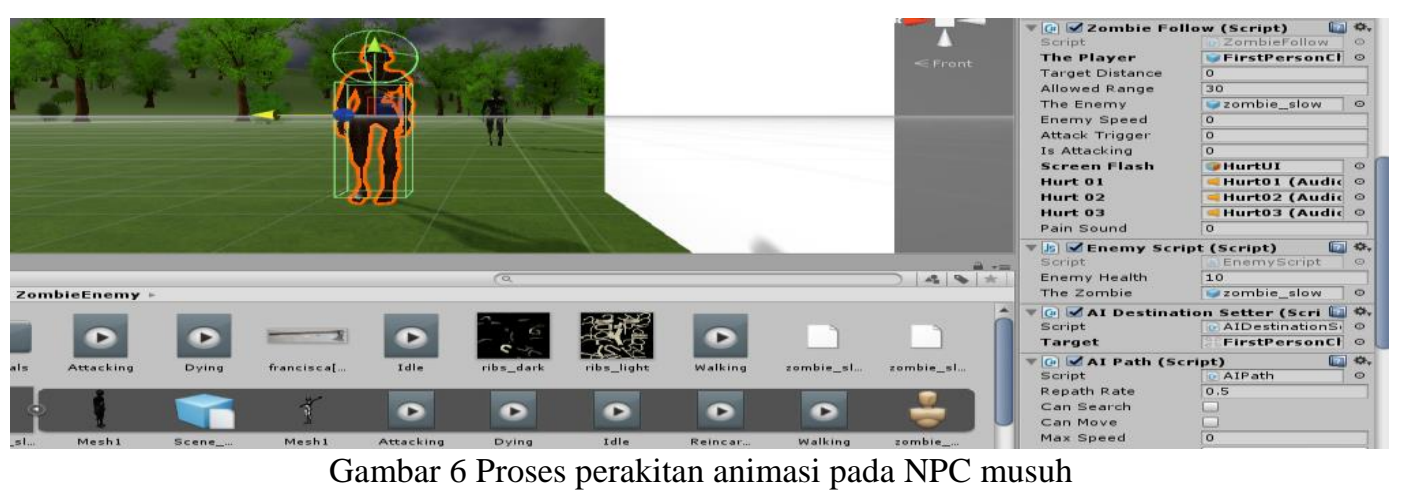

\section{E. Pengumpulan Bahan (Material Collecting)}

Bahan-bahan yang diperlukan untuk membuat game ini adalah file-file suara instrumen music, gambar, animasi dan beberapa sumber dengan menggunakan software pendukung dan sebagian diperoleh melalui internet dengan mendownload sejumlah asset berupa audio, gambar dan software Unity 3D versi 5.5.0f3.

\section{F. Perakitan}

Tahap perakitan merupakan tahap perakitan bahan-bahan yang digunakan untuk pengembangan game sehingga menjadi game yang memiliki komponen mekanisme kecerdasan buatan untuk mengatur perilaku musuh. Bahasa pemograman yang digunakan untuk implementasi Finite State Machine pada perilaku musuh di dalam perakitan ini menggunakan bahasa pemograman $\mathrm{C} \#$ atau dibaca $C$ Sharp. Kemudian bahasa pemograman ini digunakan sebagai pengontrol setiap objek game dan seluruh animasi pada karakter musuh. Berikut adalah bukti gambar screenshoot saat proses perakitan yang dapat dilihat pada gambar 6.

\section{G. Pengujian}

Pengujian dilakukan dalam mode game yaitu menguji secara keseluruhan pada perilaku NPC musuh dengan menggunakan black box testing apakah dapat menghasilkan variasi respon perilaku NPC dengan menerapkan metode Finite State Machine (FSM) berdasarkan interaksi yang dilakukan oleh player.

\section{H. Distribusi}

Setelah game jadi maka proses distribusi meliputi proses penyimpanan game dalam bentuk project game dan hasil build berupa file .exe. Penyimpanan game dalam bentuk project bertujuan agar pengembang tetap dapat menambah, mengurangi atau memodifikasi komponen atau asset dalam game sehingga dapat memudahkan dalam pengembangan dan peningkatan game yang lebih baik dari sebelumnya.

\section{HASIL DAN PEMBAHASAN}

\subsection{Hasil Implementasi Finite State Machine}

Implementasi Finite State Machine pada game zombie colonial wars, berdasarkan jarak yang sudah ditentukan yaitu dengan allowed range 30 untuk level beginner dan 20 untuk expert, jadi sebagai contoh pada level begineer jika jarak antara player dan zombie $>30$ maka zombie akan berada di state idle, jika <30 maka zombie akan mengikuti player, dan saat jarak < 1 maka zombie akan menyerang player, berikut adalah hasil FSM yang sudah diimplementasikan : 
- Zombie Idle

Keadaan idle dimana jarak antara player dan NPC berada lebih dari 30

\begin{tabular}{|c|c|c|}
\hline \multicolumn{3}{|c|}{$\checkmark$ Zombie Follow (Script) } \\
\hline Script & ZombieFollow & $\odot$ \\
\hline The Player & FirstPersonCha & $\odot$ \\
\hline Target Distance & 34.64351 & \\
\hline Allowed Range & 30 & \\
\hline The Enemy & $\forall$ zombie_slow & $\odot$ \\
\hline Enemy Speed & 0 & \\
\hline Attack Trigger & 0 & \\
\hline Is Attacking & 0 & \\
\hline Screen Flash & HurtUI & $\odot$ \\
\hline Hurt 01 & Hurt01 (Audio & $\odot$ \\
\hline Hurt 02 & \Hurt02 (Audio s & $\odot$ \\
\hline Hurt 03 & Aurt03 (Audios & $\odot$ \\
\hline Pain Sound & 1 & \\
\hline
\end{tabular}

Gambar 7 Range state idle
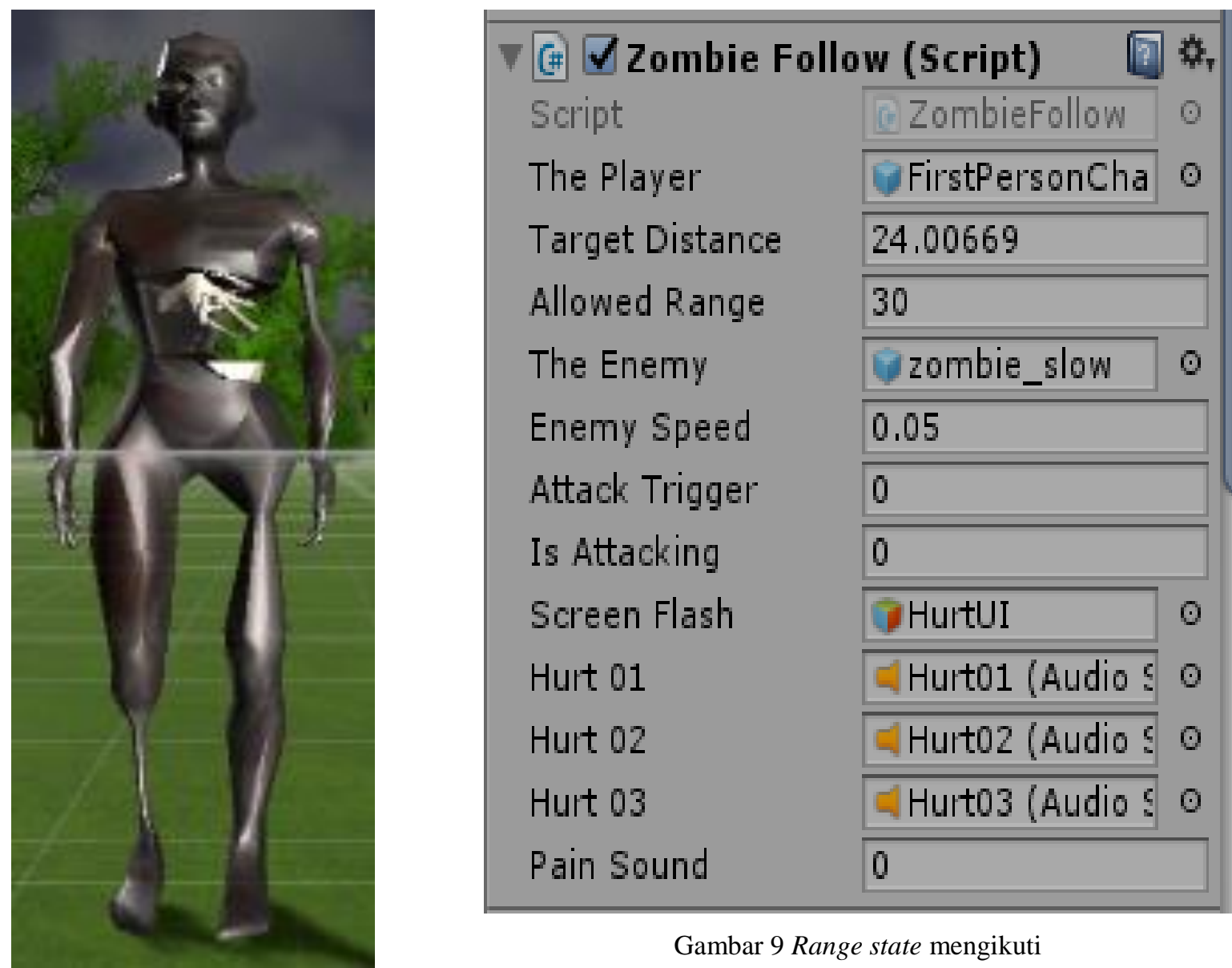

Gambar 9 Range state mengikuti

Gambar 8 Zombie Idle 
URL : https://jurnal.machung.ac.id/index.php/kurawal

- Zombie Mengikuti

Keadaan dimana jarak antara player dan NPC kurang dari 30, maka NPC otomatis akan mengikuti player

\section{- Zombie Menyerang}

Keadaan dimana jarak antara player $<1$ sehingga NPC akan berperilaku menyerang player yang sudah berada dekat sekali dengan radius serang NPC.

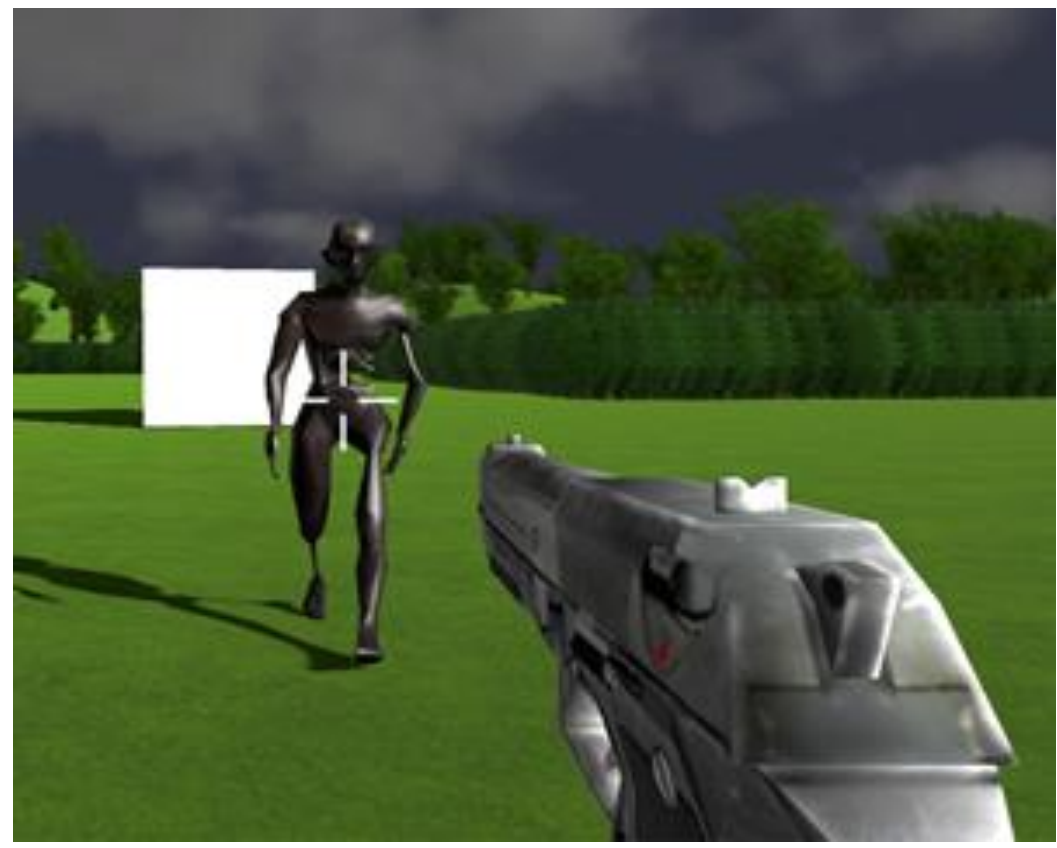

Gambar 10 Zombie Mengikuti

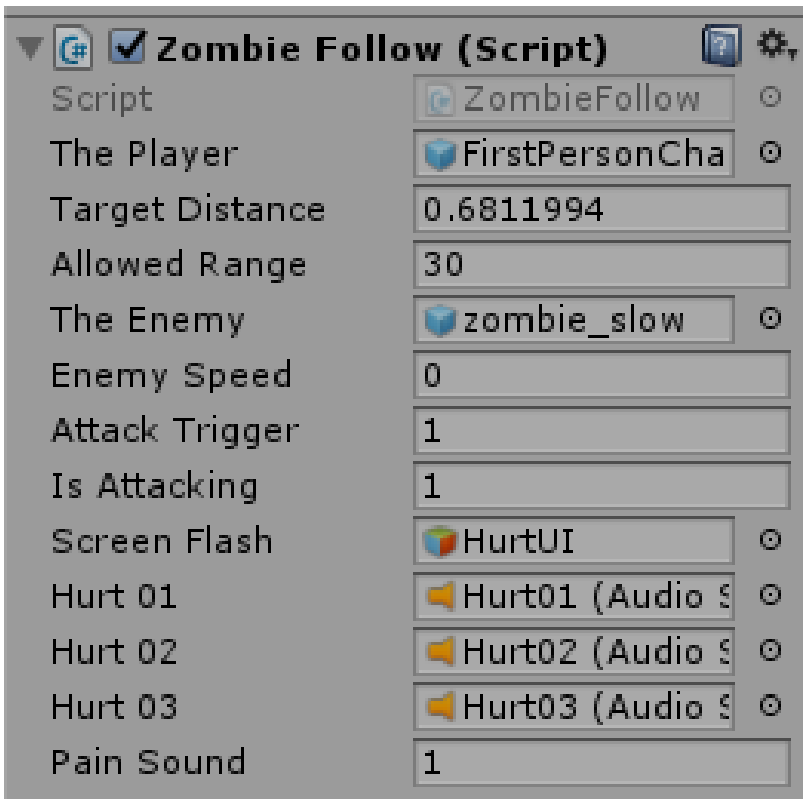

Gambar 11 Range state menyerang 
URL : https://jurnal.machung.ac.id/index.php/kurawal

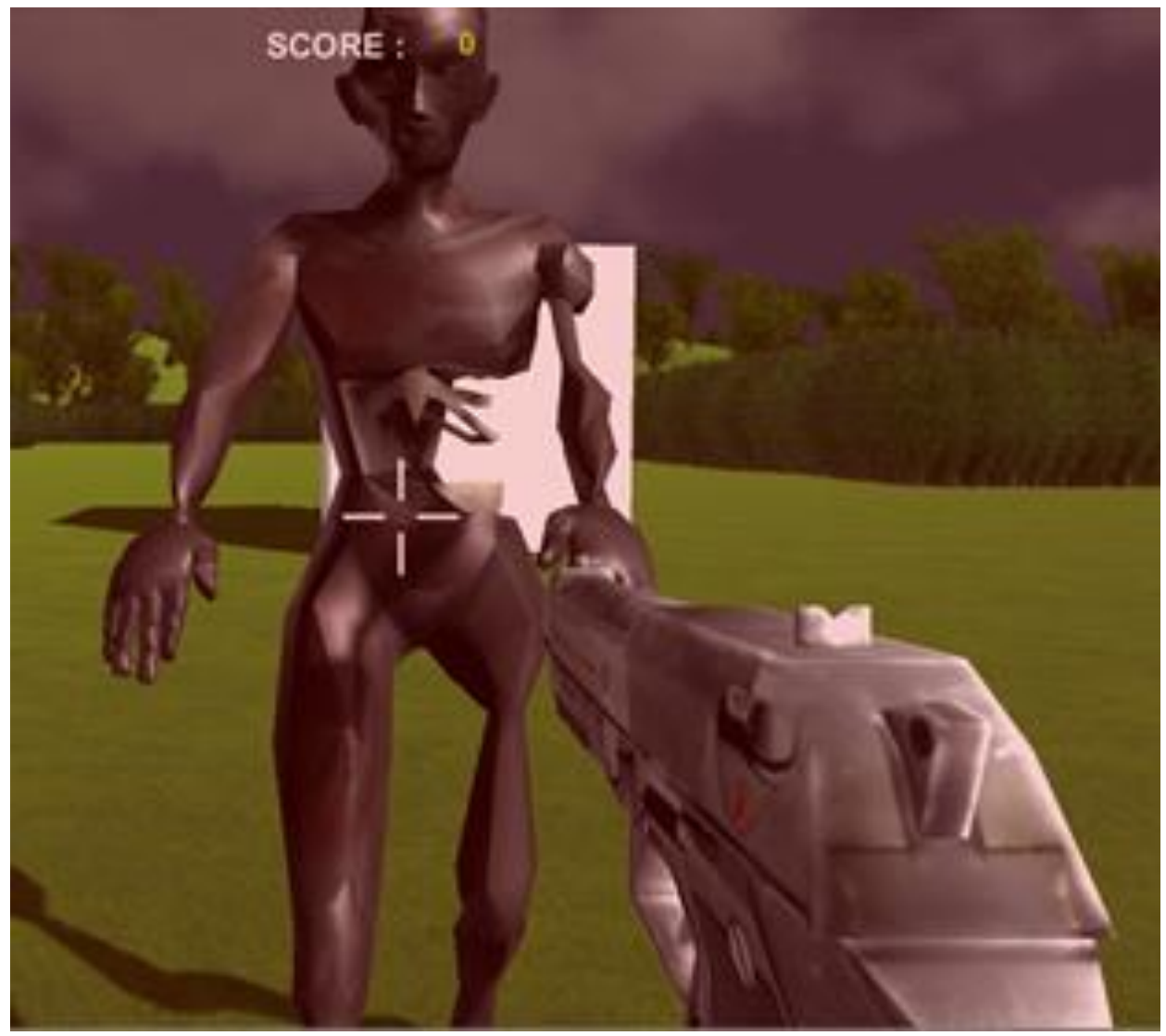

Gambar 12 Zombie Menyerang

Tabel 2 Pengujian Black Box untuk FSM

\begin{tabular}{|c|c|c|c|c|c|}
\hline $\begin{array}{c}\text { Item } \\
\text { Pengujian } \\
\end{array}$ & $\begin{array}{c}\text { Detail } \\
\text { Pengujian } \\
\end{array}$ & $\begin{array}{c}\text { Jenis } \\
\text { Pengujian } \\
\end{array}$ & $\begin{array}{c}\text { Kode } \\
\text { Pengujian } \\
\end{array}$ & Hasil & Kesimpulan \\
\hline \multirow{4}{*}{$\begin{array}{c}\text { FSM NPC } \\
\text { Level } \\
\text { Beginner dan } \\
\text { Expert }\end{array}$} & NPC Idle & Black box & $Z-0020$ & Berhasil & $\begin{array}{c}\text { Proses sesuai dengan } \\
\text { harapan }\end{array}$ \\
\hline & $\begin{array}{c}\text { NPC } \\
\text { Mengikuti }\end{array}$ & Black box & $Z-0021$ & Berhasil & $\begin{array}{c}\text { Proses sesuai dengan } \\
\text { harapan }\end{array}$ \\
\hline & $\begin{array}{c}\text { NPC } \\
\text { Menyerang }\end{array}$ & Black box & $\mathrm{Z}-0022$ & Berhasil & $\begin{array}{c}\text { Proses sesuai dengan } \\
\text { harapan }\end{array}$ \\
\hline & NPC Mati & Black box & $Z-0023$ & Berhasil & $\begin{array}{c}\text { Proses sesuai dengan } \\
\text { harapan }\end{array}$ \\
\hline
\end{tabular}

\section{Pengujian Non Fungsional}

Pengujian non fungsional dilakukan dengan menyebarkan kuisioner dengan skala likert untuk mengetahui variasi respon perilaku NPC dengan menggunakan metode finite state machine (FSM) apakah sesuai dengan penerapan metode tersebut atau tidak. Kuisioner dibagikan kepada 30 responden untuk mengetahui nilai persentase keberhasilan perilaku npc pada game "Zombie Colonial Wars". Pengujian Skala Likert game Zombie Colonial Wars disajikan pada Tabel 3 . 
URL : https://jurnal.machung.ac.id/index.php/kurawal

Tabel 3 Pengujian Skala Likert

\begin{tabular}{|c|c|c|c|c|c|c|c|}
\hline \multirow[b]{2}{*}{ No } & \multirow[b]{2}{*}{ Kriteria Penilaian } & \multicolumn{5}{|c|}{ Kategori Penilaian } & \multirow[b]{2}{*}{ Hasil } \\
\hline & & $\begin{array}{c}5 \\
\text { SS }\end{array}$ & $\begin{array}{l}4 \\
S\end{array}$ & $\begin{array}{l}\mathbf{3} \\
\mathbf{N}\end{array}$ & $\begin{array}{c}2 \\
\text { TS }\end{array}$ & $\begin{array}{c}1 \\
\text { STS }\end{array}$ & \\
\hline 1. & Game berjalan dengan lancer. & 5 & 22 & 9 & 0 & 0 & $81 \%$ \\
\hline 2. & $\begin{array}{l}\text { FPS Controller dapat berjalan sesuai } \\
\text { intruksi dari arahan keyboard pemain. }\end{array}$ & 5 & 20 & 4 & 1 & 0 & $79 \%$ \\
\hline 3. & Player dapat mengambil peluru. & 9 & 17 & 2 & 2 & 0 & $75 \%$ \\
\hline 4. & $\begin{array}{l}\text { NPC musuh idle saat jauh dari radius } \\
\text { serang player. }\end{array}$ & 3 & 24 & 3 & 1 & 0 & $79 \%$ \\
\hline 5. & $\begin{array}{l}\text { NPC musuh dapat } \text { bergerak } \\
\text { mengikuti player. }\end{array}$ & 7 & 20 & 3 & 0 & 0 & $83 \%$ \\
\hline 6. & $\begin{array}{l}\text { NPC musuh dapat mengejar player } \\
\text { saat dekat dengan radius serang. }\end{array}$ & 8 & 8 & 3 & 1 & 0 & $82 \%$ \\
\hline 7. & $\begin{array}{l}\text { NPC musuh dapat menyerang player } \\
\text { saat berada dekat sekali dengan } \\
\text { player. }\end{array}$ & 5 & 22 & 1 & 2 & 0 & $80 \%$ \\
\hline 8. & NPC dapat mati. & 12 & 13 & 5 & 0 & 0 & $85 \%$ \\
\hline 9. & Player dapat menembak NPC musuh. & 11 & 14 & 3 & 2 & 0 & $83 \%$ \\
\hline 10. & $\begin{array}{l}\text { FPS Controller dapat bergerak } \\
\text { kesegala arah. }\end{array}$ & 9 & 18 & 3 & 0 & 0 & $77 \%$ \\
\hline & a-rata & & & & & & $80 \%$ \\
\hline
\end{tabular}

$\mathrm{I}=100 /$ Jumlah Skor (Likert)

Maka $=100 / 5=20$

Hasil $(\mathrm{I})=20$

- $\quad$ Angka 0\% - 19,99\% = Sangat Tidak Setuju

- Angka 20\% - 39,99\% = Tidak setuju

- Angka 40\% - 59,99\% = Netral

- Angka $60 \%-79,99 \%=$ Setuju

- Angka $80 \%-100 \%$ = Sangat Setuju

Jumlah tertinggi $=30 \times 5=150$

Persentase diperoleh dari jumlah total nilai dari 5 butir skala likert yang diperoleh setelah itu dibagi dengan jumlah tetinggi dan dikali dengan 100. Selanjutnya nilai persentase dijumlah dan dibagi dengan jumlah pertanyaan sehingga mendapatkan hasil $80 \%$ dimana nilai tersebut masuk dalam kategori sangat setuju.

Jadi diperoleh hasil dari data 30 respoden dengan rata-rata $80 \%$ sangat setuju bahwa variasi respon perilaku NPC berjalan sesuai rencana. 


\section{KESIMPULAN}

Berdasarkan pembahasan pada implementasi metode Finite State Machine (FSM) pada perilaku NPC dapat disimpulkan bahwa game zombie colonial wars menghasilkan sebuah kecerdasan buatan pada perilaku NPC dengan mengimplementasikan metode finite state machine sehingga musuh dapat berperilaku berdasarkan interaksi yang telah dilakukan oleh player. Beberapa keadaan yang terjadi yaitu, keadaan saat player terlihat oleh musuh dan memasuki radius serang musuh maka musuh akan mengambil keputusan bergerak kearah player lalu menyerangnya dan keadaan saat musuh terkena tembakan dari player maka musuh akan mati. Hasil pengujian proses menujukkan bahwa setiap proses pada game zombie colonial wars berjalan sesuai dengan rancangan.

Hasil implementasi game ini masih jauh dari sempurna dan harus terus dikembangakan dan disempurnakan. maka perlu adanya beberapa saran untuk mengembangkan aplikasi game bergenre First Person Shooter (FPS) pada Game Zombie Colonial Wars lebih lanjut berupa penambahan level pada game, Menambahkan perilaku menyerang zombie, sehingga permainan yang dihasilkan lebih menarik pemain. Menambahkan 2 atau 3 lagi NPC dalam sebuah tim, sehingga diharapkan strategi menjadi lebih menarik dengan memberikan perilaku yang berbeda-beda pada setiap NPC.

\section{REFERENSI}

[1]Annubaha, Chakim. 2014. Implementasi Finite State Machine (FSM) Pada Game 3D Edukasi Bahasa Arab. Malang: Universitas Islam Negeri Malang.

[2]Asmiatun, Siti. 2016. Implementasi Klasifikasi Bayesian Untuk Strategi Menyerang Jarak Dekat Pada Npc (Non Player Character) Menggunakan Unity $3 d$.

[3]Fadel Marzian, Mukti Qamal.2016. Game Rpg "The Royal Sword” Berbasis Desktop Dengan Menggunakan Metode Finite State Machine (Fsm).

[4]Ganzala, Fauzan. 2016. Perilaku Non Playable Character (NPC) Musuh Pada Game Sepeda Menggunakan Fuzzy State Machine (FuSM). 2016

[5]Purnamasari, Yuli, Mario dan Rachmansyah. 2015. Aplikasi Game Edukasi Sistem Tata Surya Dengan Menggunakan Metode Line Renderer Berbasis Unity 3D. Palembang: STMIK GI MDP.

[6]Rosikhan Maulana Y. 2015. Unity 3D - Game Engine.

http://www.hermantolle.com/class/docs/unity-3d- game-engine/. Diunduh pada tanggal 2 Maret 2016 pukul 16.45 WIB 